\title{
Does perceptual content have to be objective? A defence of nonconceptualism
}

\author{
Schmidt, Eva
}

\begin{abstract}
In this paper, I discuss the conceptualist claim that we cannot speak of perceptual content unless we assume it is objective content. The conceptualist argues that only conceptual content can meet the requirement of being objective, so that the view that perceptual experience has nonconceptual content is not tenable. I start out by presenting the argument from objectivity as it can be found in McDowell (Mind and world, Harvard University Press, Cambridge, 1994b). I then present the following objections: First, perceptual objectivity cannot be due to the perceiver's conception of objectivity; and second, even nonconceptual capacities of the individual cannot and need not be appealed to in order to account for objective perceptual content
\end{abstract}

DOI: https://doi.org/10.1007/s10838-015-9289-5

Posted at the Zurich Open Repository and Archive, University of Zurich

ZORA URL: https://doi.org/10.5167/uzh-141262

Journal Article

Accepted Version

Originally published at:

Schmidt, Eva (2015). Does perceptual content have to be objective? A defence of nonconceptualism. Journal for General Philosophy of Science, 46(1):201-214.

DOI: https://doi.org/10.1007/s10838-015-9289-5 


\title{
Does Perceptual Content Have to Be Objective? A Defence of Nonconceptualism
}

\author{
Eva Schmidt
}

Published online: 19 March 2015

(C) Springer Science+Business Media Dordrecht 2015

\begin{abstract}
In this paper, I discuss the conceptualist claim that we cannot speak of perceptual content unless we assume it is objective content. The conceptualist argues that only conceptual content can meet the requirement of being objective, so that the view that perceptual experience has nonconceptual content is not tenable. I start out by presenting the argument from objectivity as it can be found in McDowell (Mind and world, Harvard University Press, Cambridge, 1994b). I then present the following objections: First, perceptual objectivity cannot be due to the perceiver's conception of objectivity; and second, even nonconceptual capacities of the individual cannot and need not be appealed to in order to account for objective perceptual content.
\end{abstract}

Keywords Nonconceptual content $\cdot$ Perceptual experience $\cdot$ Objectivity $\cdot$ Intentionalism

\section{Some Background}

The argument I discuss here is taken from the debate between conceptualism and nonconceptualism over the question of whether the content of perceptual experience is conceptual or nonconceptual. ${ }^{1}$ That experience has nonconceptual content is typically taken to mean that I can have a certain experience even if I do not possess the concepts that would specify its content. By contrast, to say that experience has conceptual content is taken to mean that in order to have an experience, I need to possess the concepts that characterize its content.

\footnotetext{
${ }^{1}$ Some of the major players in the debate are Christopher Peacocke, José Bermúdez, and Michael Tye on the nonconceptualist side, and John McDowell and Bill Brewer on the conceptualist side (Brewer 1999; McDowell 1994b; Bermúdez 2003; Peacocke 1992; Tye 1995).
}

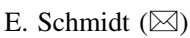

Philosophisches Institut, Universität des Saarlandes, 66123 Saarbrücken, Germany

e-mail: eva.schmidt@mx.uni-saarland.de 
As presented so far, what is at stake in the debate is whether possession of conceptual abilities is required for a subject to undergo a perceptual experience. Byrne (2005) calls nonconceptualism understood thus the "state view" and argues that the truth of the state view has no bearing on whether the content of an experience has a conceptual structure or not, i.e., on whether the "content view" should be accepted. For example, we can ascribe a Fregean proposition (which is the standard example of a conceptually structured content) to an experience even if the subject lacks the conceptual abilities characterizing this content.

In my (forthcoming), I point out that what is relevant is not whether the subject possesses certain conceptual abilities, but whether she exercises them. I argue that if the relevant conceptual abilities have to be exercised in undergoing a mental state, then it has conceptual content. Vice versa, if no conceptual abilities have to be employed in undergoing a mental state, then its content is nonconceptual. This is not the place to present this argument.

Instead, I will assume throughout that, according to conceptualism, the relevant conceptual abilities have to be exercised in a perceptual experience and, consequently, that experience has conceptual content. ${ }^{2}$ I will assume that the nonconceptualist holds that no conceptual abilities need to be exercised in undergoing a perceptual experience and thus also that its content is nonconceptual. That is, I will pit both the content and the state view of nonconceptualism against both the content and the state view of conceptualism.

\section{The Argument}

The argument from objectivity ${ }^{3}$ that I discuss here is an argument in favor of conceptualism. In this paper, I will elucidate the different steps of the argument and argue that it is not a threat to nonconceptualism.

The argument consists of two steps. In the first step, the conceptualist attempts to show that we cannot speak of content of a perceptual experience unless it represents an objective, mind-independent world to the subject as objective (called 'step one' below). In the second step, he argues that there can be no representation of the world to the subject as objective by anything less than a mental state with a conceptual content ('step two'). The conclusion is that there can be no nonconceptual perceptual content-instead, it has to be conceptual. To put it even more succinctly, the argument is: no conceptual structure, no objectivity; no objectivity, no content.

Let's turn to step one: Why does the conceptualist require perceptual content to be objective? McDowell in particular is motivated by the Kantian image of blindness, a blindness that might threaten perceptual experience: "To say that an experience is not blind is to say that it is intelligible to its subject as purporting to be awareness of a feature of

\footnotetext{
${ }^{2}$ McDowell, too, requires more than concept possession. According to him, however, conceptual abilities have to be drawn on or actualized in perceptual experience. This way, he tries to capture that it is not under the active control of the perceiver how conceptual abilities are operative in perceptual experience. I cannot discuss the fine-grained distinction between exercising and actualizing conceptual abilities here. At any rate, what is important is that McDowell and I agree that mere possession of the relevant concepts does not guarantee that a mental state has conceptual content. Rather, these concepts have to be operative in undergoing the experience.

3 The main proponent of the argument is McDowell (1994b). There are some passages in Brewer (1999) dealing with the same ideas; otherwise, most of the literature consists in defenses of nonconceptualism against the objection. See, e.g., Burge (2009, 2010); Peacocke (1992, 1994, 2001a, 2001b, 2003).
} 
objective reality: as a seeming glimpse of the world" (McDowell 1994b, 54). ${ }^{4} \mathrm{We}$ "conceive experience as awareness, or at least seeming awareness, of a reality independent of experience" (31). He holds that in perceptual experience, "the relevant conceptual capacities are integrated into spontaneity at large, in a way that enables the subject to understand experiences in which those conceptual capacities are drawn into operation as glimpses, or at least seeming glimpses of the world: takings in, at least seemingly, of aspects of a reality that goes beyond what is manifest in the experiences themselves." (31f.)

Part of McDowell's claim is the phenomenological observation that perceptual experiences seem to confront us with a mind-independent world. ${ }^{5}$ They purport to represent a reality that goes beyond experience itself, a reality that we can grasp in thought. As subjects of perceptual experience, it strikes us not that we have certain raw feels, say, but that we are confronted with a world external to and independent of us.

One part of the point is that talk of representation and empirical content is unintelligible unless we presuppose that there is, or seems to be, something beyond the experience (viz., an objective world) that is represented. The other part is that genuine representation of the world to the subject means that she appreciates (it is "intelligible" for her) that she is, or seems to be, confronted with a mind-independent world. Experience purports to present the world to the subject-it has to register with the subject that she is apparently confronted with a certain way the world is.

From these quotes, three requirements on perceptual objectivity can be isolated for step one-genuine perceptual content must be objective: (1) features of the mind-independent world must be represented ${ }^{6}$; (2) they must be presented to the subject; for otherwise, she would not be able to grasp that what is presented to her is apparently part of a larger reality, and (3) they must be represented as objective. This last requirement captures McDowell's idea that subjects of perceptual experience take themselves to be confronted with a world whose existence does not depend on their experience, that they appreciate the apparent fact that their experiences present them with a mind-independent world. ${ }^{7}$

Step two consists in the claim that only conceptual content can be objective-only conceptual states are capable of (apparently) presenting a mind-independent world to the subject as objective. How does McDowell argue for this claim? According to him, (A) experience can (apparently) present the world as objective to the subject only if it is integrated into the subject's overall system of concepts and beliefs, into her world-view as of an objective world (32). ${ }^{8}$ (B) The required integration is possible only if experience has conceptual content.

As to (A), we can see why integration into a world-view might play a role for perceptual objectivity by considering the third element of objective perceptual content. Plausibly, the world will be perceptually presented to the subject as objective only when integrated into a

\footnotetext{
${ }^{4}$ From here on, all bare page references will be to McDowell (1994b).

${ }^{5}$ He relies explicitly on phenomenological considerations in his (1994a).

${ }^{6}$ Note that perceptual experience can misrepresent: Features of a mind-independent world may be represented where none are present.

7 While the world "is the bit of objective reality that is within her perceptual and practical reach" (116) for subjects who are able to appreciate its objectivity, it is not there at all for animals who are unable to do so. McDowell denies that such animals have experiences with representational content-instead, he ascribes mere "perceptual sensitivity" to them (121).

${ }^{8}$ I will leave out the 'as of an objective world' from now on. For McDowell, talk of a world-view already implies that it is a view of a world as objective-otherwise, there could not be a world and a view of it. I will follow him in his use of "world-view".
} 
web of beliefs such as that the world is mind-independent, that there is a distinction between her consciousness and the world, or that the same reality can be experienced from more than one perspective. To feel the appeal of this claim, you have to take seriously the conceptualist's worry about how perceptual experience could succeed in being more for $a$ subject than mere (non-representational) raw feels in the first place. McDowell's answer is that it can be a glimpse of mind-independent reality only against the background of the subject's understanding that it is such a glimpse. ${ }^{9}$

But how does this need for integration into a world-view connect to the claim (B) that perceptual content must be conceptual? There are two ways to motivate the need for conceptual content: First, the content of a perceptual experience, taken in its entirety, must bear rational relations to belief contents to allow for the experience and its content to be integrated with the subject's beliefs and their contents; rational relations require conceptual contents. Second, the integration can be achieved immediately via the elements constituting a perceptual content, but only if they are concepts. For only then can they be terms in a conceptual repertoire presupposing an objective reality.

Let's turn first to how the content of a perceptual experience, taken as a whole, can be integrated into a world-view. What exactly are the purported rational relations between (the contents of) perceptual experience and empirical belief? Perceived facts, via perceptual experience, exert rational constraints on what is rational to believe, and the belief system has to be constantly adjusted to the contents of the subject's perceptual experience. For instance, when I see, upon taking a closer look, that there is a dog in front of me, not the sheep that appeared to be there originally, I have to abandon my belief that there is a sheep in front of me to be rational. As per (A), in the opposite direction, the contents of our beliefs concerning the mind-independent world (our world-view) shape the contents of our experiences.

Rational relations in both directions are needed to create an integrated world-view, which includes experiences whose content itself is shaped by the world-view so as to represent the world to the subject as objective. If the relation between experience and belief were only causal, for instance, the world would not be able immediately to strike the perceiver as objective in experience. The best the subject might hope for is meta-beliefs to the effect that particular perceptual experiences which cause certain beliefs are themselves caused by certain features of an objective reality. ${ }^{10}$

What connects this to step two (B) is McDowell's claim that only mental states with conceptual content can be rationally related to beliefs (52). Following Davidson (1983/ 2008), he holds that rational relations can only obtain between items with conceptual/ propositional content. Perceptual experience, conceived of as a state with nonconceptual content, must remain outside the "space of reasons" (5) - the only relations that can obtain between experience and belief on this picture are causal relations.

Putting things together, perceptual objectivity relies on the rational integration of entire contents of perceptual experiences into the subject's world-view, and rational integration can only work on conceptual contents. So, perceptual objectivity presupposes that perceptual experience has conceptual content.

\footnotetext{
9 Similar claims can be found in Strawson (1959) and Quine (1960). The nonconceptualist views of Evans (1982) and Peacocke $(1994,1992)$ are also influenced by this requirement on objectivity. For a helpful summary of the tradition and an interesting criticism, see Burge (2010, 2009).

${ }^{10}$ McDowell would not even grant this much, for without rational integration, our beliefs cannot have empirical content.
} 
The other way to achieve rational integration of a perceptual content into a world-view is not through the relations between particular beliefs and particular experiences (and their contents) as just described, but via the concepts constituting perceptual contents (29-36). This is a matter of how the elements making up a perceptual content are related to the perceiver's world-view, as reflected by her conceptual repertoire. A perceiver's overall conceptual system incorporates the idea that she is faced with an objective world; her empirical concepts are concepts as of an objective reality-they are concepts as of mindindependent objects, relations, and properties. So her experience, if its content is constituted by concepts that are shaped by their relations to a conceptual system that presupposes the mind-independence of the world, will represent the world as objective. This is so because "the rational connections of the concept enter into shaping the content of the appearance so that what appears to be the case is understood as fraught with implications for the subject's cognitive situation in the world" (32).

If perceptual content is nonconceptual, on the other hand, it is impossible for this kind of intimate relation between a subject's conceptual repertoire and her perceptual contents to obtain: Since nonconceptual perceptual contents are not constituted by concepts, they cannot be rationally integrated into the her world-view in virtue of their conceptual constituents. They cannot be objective in this way. Thus, steps two (A) and two (B) are spelled out as follows. (A) To represent the world as objective to the subject, the very elements constituting the perceptual content in question must be incorporated into a world-view. But (B), for a perceptual content's elements to be so integrated, these elements must themselves be concepts, for otherwise they cannot be part of a conceptual repertoire that presupposes a mind-independent world.

Let me conclude my discussion with a concise statement of the argument:

(Step one) A perceptual experience can have genuine content only if it represents the world to the subject as objective.

(Step two (A)) A perceptual experience can represent the world to the subject as objective only if it is rationally integrated into a world-view.

(Step two $(B)$ ) A perceptual experience can be rationally integrated into a world-view only if its content is conceptual.

(Conclusion) A perceptual experience can have genuine content only if this content is conceptual.

I will now discuss two objections to the argument. The first objection purports to show that the subject can appreciate and thus perceive the world as objective (as required by the conceptualist) without a belief- and concept-based world-view. The second objection points us towards a weaker notion of objectivity that can provide for perceptual content without invoking any further individual-level capacities.

\section{The First Objection: No Need for a Belief-Based World-View}

Plausibly, a subject's beliefs are objective partly because they (and their contents) are rationally integrated into a world-view and because the concepts constituting their contents are elements of a web of concepts which is shaped by the presupposition that the world is objective. Prima facie, it is appealing to transfer this picture to perceptual experience.

To test the plausibility of this transfer, let's consider an entrenched solipsist's perceptual experience. The solipsist falsely believes that there is no external world and that there are no objective facts about the world to know. She thinks that all there is is her mind, her 
experiences and her beliefs; she believes that there are only subjective facts, facts about herself. According to her, perceptual experience does not present a mind-independent environment to her-she has no world-view. ${ }^{11}$ She conceives of her perceptual experience as constituted by qualia or raw feels that are not about anything outside of her mind.

Does her perceptual experience have a content? Does the objective, mind-independent world seem to strike her in any way in perception, or does she just appear to be confronted with subjective facts about herself? If the content of the solipsist's perceptual experiences is indeed determined by her overall belief system and conceptual repertoire with which her experiences are integrated, one might expect them not to represent anything beyond her. In particular, if perceptual experience represents a mind-independent world to the perceiver only in virtue of its integration with her world-view, the solipsist's perceptual experience does not even purport to present her with an objective world out there-it does not seem to her as though she is presented with a mind-independent world.

Yet leaving aside the conceptualist's presuppositions, I think the most plausible story we can tell about this confused individual is that her situation is somewhat parallel to that of the informed perceiver when looking at the Müller-Lyer drawing: He knows that both lines are equally long, but he cannot help but experience them as being of different lengths. This is so because his perceptual experience purports to have empirical import, prior to and at least partly independently of what he believes about the world.

The solipsist thinks she knows that there is no objective reality; but she cannot shake the impression, in undergoing her experience, that there is an objective world that she perceives. Again, the reason for this is that experience, all by itself, purports to be about an objective world. The solipsist can go no further than to have a belief system and a web of concepts as of a world consisting only of subjective facts about herself. Moreover, she can try to take a certain attitude towards her perceptual experience and try to take it as nothing but raw feels (for instance, imagine that she has what we would describe as a visual experience as of a rock flying right at her face. She can try to convince herself that she is merely experiencing some interesting visual qualia.). But this will not change the fact that her perceptual experiences, prior to and independently of her solipsist assumptions, will purport to present her with things in the objective world (correspondingly, she will feel the strong urge to duck because there seems to be a rock coming at her). ${ }^{12}$

The conceptualist can try to accommodate my claims by saying that no one can ever be a solipsist all the way to the ground level. He might argue that the content of any perceiver's experience is constituted by a special level of concepts that take hold of her environment directly. ${ }^{13} \mathrm{He}$ can concede that the subject cannot help the actualization of these concepts in perception, and so she cannot help being a realist about the world at the most primitive level. With this move, however, my opponent loses the apparent advantage

\footnotetext{
11 See footnote 8 .

12 One might object that her urge to duck will be due to her anticipation of painful qualia, and nothing more. But I do not think that this is plausible. Just as it is beyond the subject's control that she will raise her foot reflexively when stepping into a nail, so it is not under her control that she will duck in expectation of being hit by a rock because her visual experience represents a rock to be flying at her face.

Plausibly, she will believe that it appears as though there is a rock flying at her face on the basis of her experience. This goes to show that her experiences help determine what the solipsist believes. But on the argument presented above, her beliefs should influence the content of her perceptual experiences as wellher conviction that there is no external world to be represented should prevent her experience from making it appear as though there is a rock flying in her direction in the first place.

13 Brewer (1999) and McDowell (1994b) could use their account of demonstrative perceptual content to support this claim. The corresponding debate lies outside the scope of this paper.
} 
of his view that perceptual experience is objective because the concepts constituting its content are part of a web of concepts presupposing an objective world, and because the perceptual content is rationally integrated into a world-view. For the special basic concepts involved in experience (and the experience itself), as they are conceived of now, are of an objective reality independently of the subject's world-view.

Alternatively, the conceptualist could deny that the die-hard solipsist's perceptual experience is as of an objective reality. It only presents the subject with subjective facts about her own experience. I have used an analogy with our lack of control over our experience in the case of the Müller-Lyer illusion to discourage this move. Nonetheless, the conceptualist may be willing to bite the bullet and hold that the solipsist's perceptual experiences do not appear to her to have any empirical import. Note that this insistence conflicts with further plausible assumptions, such as that perceptual experience is transparent. Introspectively focusing on my visual experience of a sheep, for instance, I seem to be confronted with an external object (the sheep) and its properties. Further, it is impossible for me to pin down any properties that appear to be properties of my experience rather than properties of the sheep (see Crane 2011). Now, if the solipsist's experiences do not even purport to confront her with a mind-independent reality, it follows that they are not transparent, not even in the weaker and uncontroversial sense that they seem to confront her with external objects.

Further, there is a tension here between two elements in the conceptualist's view: Between McDowell's plausible insistence that, in experience, the perceiver finds herself "saddled with content" (McDowell 1994b, 10), i.e., that she has no control over what she is confronted with perceptually, and the suggested consequence of his view, that by becoming a committed solipsist, she can cast off the apparent empirical import of her experiences, which implies that it is up to her after all what she is confronted with in experience.

So, we should look elsewhere to explain the objectivity of perceptual experience. That experience plausibly represents the mind-independent world to the solipsist despite her lack of a world-view shows that integration into a belief- and concept-based world-view is not necessary for the objective import of perceptual experience. The solipsist case motivates a rejection of step two (A), provided we understand world-views as concept- and belief-based phenomena. This rejection can be complemented by introducing a less demanding kind of "world-view" into which experience needs to be integrated to be objective. I will discuss this option next.

The link between step one and step two of the argument from objectivity is provided by the notion that perceptual experience presents the world to the subject as objective. This is to say that the perceiver is not blind to the world-she has to take the world to be objective, or appreciate the apparent mind-independence of the world in experience.

The view that I will present now concedes that perceptual content requires the subject's appreciation of the world as objective, but holds that this can be achieved without a beliefor concept-based world-view. Rather, what is needed is the nonconceptual ability to build up a cognitive map of one's environment on the basis of perceptual experience. ${ }^{14}$

As stated above, on McDowell's view, experience can present the world as objective to the subject only when integrated into a world-view. In order to appreciate the fact that perceptual experience represents the objective world to her, the subject has to understand that the world is independent of her mind and of her perceptual perspective on the world.

14 Note that in the end, I will not endorse this view: I hold that not even this much is needed for experience to have a content. I will get to this in the next section. 
The nonconceptualist alternative is exemplified by Peacocke's (2003) view. He holds that the subject has to be able to keep track of her changing position in her environment to have genuinely spatial perceptual contents, but he provides an account of how this is possible without a concept of objectivity. In Peacocke (2003, 319), he points out that the resources for explaining how a subject can keep track of her position in space are provided by the perceptual experience's nonconceptual content itself, which Peacocke (1992) accounts for in terms of scenario content. A scenario content is characterized by its origin, in relation to which the perceived properties and relations are arranged along axes. For instance, my visual experience of a sheep off to my left represents the sheep and its properties, as well as other properties of my surroundings, at a certain distance and angle along with axes with respect to me as the origin.

Building up from this, a subject can come to what Peacocke (2003) calls a nonconceptual notion hier. The subject possesses hier if she represents the origin of scenario contents as hier-if she represents things that bear relation $R$ to the origin of the scenario content as standing in $R$ to hier. Moreover, she has to update the relations things bear to hier as she moves around in space. When the subject moves and therefore the relation of a perceived object to the origin of the scenario content changes from $R$ to $R$ ', she has to update her representation of this object's relation to hier from $R$ to $R$ '. For instance, when I move closer to the sheep, I represent the sheep as moving closer to hier.

In this account, the subject possesses a cognitive map of her environment, in relation to which she is able to update her own position. What is central to this account of objectivity is a representation of the perceiver's position as related to her immediate surroundings, a representation that stays the same across changing perceptual experiences.

Let me be clear that hier is not a concept. One reason why not is that a subject can possess hier without having any reflective-critical abilities that would be needed for her to evaluate her mental contents and to consider whether she should take them at face value or not. Hier can be had by a subject who can do no more than uncritically accept any perceptual content she is presented with, as long as she is able to update hier in relation to her perceived environment. So, this notion does not meet McDowell's plausible criterion on what it takes to possess a concept, viz. the self-critical ability to use the concept in thought to revise one's empirical beliefs in response to perceptual experience (McDowell 1994b, 49, 66).

Peacocke's view is an example of how the appreciation of the world as objective can be made possible without appealing to a concept- and belief-based world-view. It is an attempt to capture what might seem right about step two (A) (of rational integration into a world-view) in nonconceptual terms: A perceiver's experiences are integrated into her cognitive map of her environment. This cognitive map constitutes her grasp of the mindindependence of her surroundings. It can be seen as a less demanding kind of world-view, for it involves the integration of the perceiver's experiences into one cognitive map of her mind-independent environment.

Taken together with the fall-out from the solipsist case, the result is that perceptual representation of the world to the subject as objective can be had without a belief- and concept-based world-view, as long as the perceptual experience is integrated into a cognitive map. So far, step one remains untouched, and step two (A) is modified so as to allow for integration into a cognitive map as a way of being integrated into a world-view.

In contrast to the described strategy, I will argue in the following that the nonconceptualist need not grant her opponent even this much. The subject's appreciation of the mind-independence of the world in terms of a cognitive map is not necessary for the phenomenally conscious perceptual experience of adult humans. To prepare the ground for 
this, I will first present an alternative notion of objectivity which does away with the perceiver's appreciation of the world as objective.

\section{The Second Objection: No Need for Presentation as Objective}

I believe that everyone has to allow that perceptual objectivity in some sense is indeed needed for genuine content. However, objectivity should not be conceived of in the demanding way suggested by the conceptualist. Recall his three elements of perceptual objectivity: (1) Features of the mind-independent world must be represented; (2) they must be presented to the subject; and (3) they must be represented as objective. Call the conceptualist's notion of objectivity

(Objectivity $_{1}$ ) A perceptual experience is objective ${ }_{1}$ if and only if it represents objective features of the world to the subject as objective.

The weaker notion of perceptual objectivity I propose is

(Objectivity $_{2}$ ) A perceptual experience is objective 2 if and only if it represents objective features of the world to the subject.

In the next few paragraphs, I will elucidate the notion of objectivity 2 and compare it with the previously proposed notion of objectivity ${ }_{1}$.

The first element of perceptual objectivity that the nonconceptualist ought to accept is that it should represent objective features of the world, for we cannot understand how experience can have empirical content unless we assume that it takes hold of the objective world (33/34). If we were to deny that experience represents the objective world, we would thereby also deny that it has empirical content. It does not make sense to say that experience has representational content while denying that it represents something, and what it represents is (at least in standard perceptual experience) what is or could be the case in the world.

This can be further motivated by an appeal to the distinction between sensory states that are sensitive to distal stimuli and ones that are sensitive merely to proximal stimuli (Proust 2000). For instance, the retina of the human eye is sensitive to changes in the intensity and frequency of the light waves that strike the retina. But it does not represent anything beyond these proximal stimuli, such as objects or properties at a certain distance from the perceiver.

Human subjects, by contrast, can represent distal stimuli such as (features of) threedimensional objects at a distance from their perceptual organs, and they can represent them as constant even as they themselves move around their environment. With this ability, we get a distinction between states of the perceiver and states of the environment, between the perceptual states themselves and what they represent, i.e., a distinction between mind and mind-independent world.

Let me clarify that representation of constant three-dimensional objects at a distance is not necessary for genuine perceptual content. In auditory experience, for instance, sounds are represented. Plausibly, sounds are not three-dimensional objects. What is crucial for perceptual objectivity is that certain constant features are represented such that they appear to be a certain way independently of the position and states of the perceiver. In vision, this is typically tied to representation of distal three-dimensional objects. But it is at least conceivable that all that is represented to be out there are constant two-dimensional shapes, independently of the situation of the perceiver. 
The second requirement on genuine content that the nonconceptualist should grant the conceptualist is due to the fact that our topic is the content of phenomenally conscious perceptual experience of adult humans. So, what we need are necessary conditions for phenomenally conscious content. That is, we should accept the requirement that the subject be presented with apparent features of her environment.

Perceptual experience takes place at the level of the individual, not at the level of one of its parts-e.g., at the level of some perceptual module or system. It is the subject who is phenomenally conscious of her surroundings, not one of her subsystems. Moreover, as Burge $(2010,376)$ argues, perception is constitutively tied in with the individual's agency and with her specific perceptual perspective on the world. It should be common ground between the conceptualist and the nonconceptualist that in perceptual experience, the world strikes the perceiver as being in a certain way.

So, the nonconceptualist should not take issue with the first two elements of perceptual objectivity as proposed by the conceptualist. The only thing that objectivity ${ }_{1}$ adds to objectivity $y_{2}$, then, is the idea that the subject has to take the world to be constituted by spatially arranged objects, on top of this (hence the 'presents ... her environment as objective'). As explicated above, the subject's appreciation of the mind-independence of the world can be either in terms of a world-view or in terms of a (nonconceptual) cognitive map.

I have already rejected the necessity of integration into a belief- and concept-based world-view for genuinely objective content. But I still need to show that objectivity 2 is a genuine alternative to objectivity ${ }_{1}$, where the subject's appreciation of the world as objective is spelled out in terms of the experience's integration with her other experiences via a cognitive map.

Here is why objectivity ${ }_{1}$ (supplied by the cognitive-map account) is not necessary for perceptual experience to have a content. Imagine a subject with a severe case of anterograde amnesia. She has completely lost her short-term memory and is unable to remember anything she perceives. At some point, she will have lost her ability to build up a cognitive map of her surroundings and to locate herself on this map just because her short-term memory is too bad to support a permanent representation of her environment through which she moves. At this point, her perceptual experiences are not objective ${ }_{1}$ anymore. $^{2}$

Still, I find it highly counterintuitive to claim that any one of her perceptual experiences fails to represent her environment. The more plausible description of her situation is that she genuinely perceives her surroundings at any given moment; she simply lacks the shortterm memory to combine her perceptions into one persisting cognitive map. Her impairment concerns her memory, not her ability to perceive the mind-independent world.

The problem for Peacocke might be solved by pointing out that the amnesia patient will still have concepts of and beliefs about an objective world and that her perceptual experiences will therefore still be embedded in a world-view. More generally, one might claim that, for genuine perception, some sort of grasp of objectivity by the subject is necessary; it is irrelevant whether this is conceptual, whether it is constituted by an ability to locate oneself on a cognitive map of one's environment, or both.

This is not convincing. Rather, the amnesiac case brings out a deeper question about the requirement of representation to the subject as objective for perceptual content: Why should we require anything more sophisticated of a perceiver with representational perceptual experiences than just the ability to have an experience of her environment at a particular time? Why is representation of features of an objective world to the subject (without adding 'as objective') not good enough? 
More trouble for my position might be caused by Burge $(2009,2010)$. He suggests that we need perceptual memory (and perceptual anticipation) for objective representation. If I read him correctly, the subject (at the individual level) is required to have capacities for memory and anticipation in order to perceive constant features of objects as such over longer stretches of time. ${ }^{15}$

Burge's point is related to the idea that the perceiver's experience needs to be integrated into a cognitive map of her environment for it to have genuine content - such a cognitive map relies on the subject's memory of her previous perceptual experiences to create an integrated representation of her surroundings over time. This is needed for the subject to appreciate her environment as objective, and thus for objectivity ${ }_{1}$. The question is whether it is really necessary for the perceptual experience to have representational content.

To lend further support to my claim that additional individual-level capacities, memory in particular, are not needed for perceptual experience with genuine content, let me add another twist to the amnesiac case.

Imagine that, at $t_{1}$, the amnesia patient is facing an apple, but she has no short-term memory of her recent past. So her perceptual state (if I may call it that) which would, under better circumstances, represent the apple, is not integrated into a cognitive map at this point. If objectivity ${ }_{1}$ is needed for perceptual experience with representational content, the amnesia patient does not have a content-bearing experience of the apple at $t_{1}$.

Now imagine that exactly at $t_{1}$, her capability to form short-term memories is miraculously restored. As a consequence, when she is still facing the apple at $t_{2}$ shortly thereafter, she has a perceptual experience representing the apple to her. For with her shortterm memory restored, she now remembers her perceptual state at $t_{1}$, so that her experience at $t_{2}$ is integrated into a cognitive map of her environment, including the apple.

What is very strange about this account is that-as described-the amnesiac now has a content-bearing memory of her perceptual state at $t_{1}$. Without it, she would not yet be able to construct a cognitive map of her environment, and thus would not have an experience representing the apple at $t_{2}$. This suggests that, looking back from her situation at $t_{2}$, her perceptual state at $\mathrm{t}_{1} i$ s an experience with phenomenally conscious content that presents the apple to her. For how else could she remember what she perceived? But how can this be the case if her perceptual state was not an experience presenting her with the apple at $t_{1}$ ?

Excluding backwards causation, it either must have been a perceptual experience presenting her with the apple originally, or the healed amnesia patient's memory, at $t_{2}$, of her previous perceptual state as presenting her with an apple, must be mistaken. The defender

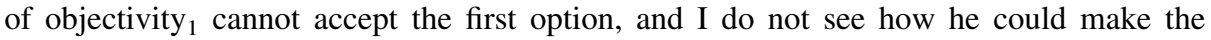
second option work. For how could the amnesiac have a mistaken memory (with phenomenally conscious content) of a perceptual state that was not phenomenally conscious, and had no content presenting her with an apple, at the time? This is especially problematic since the phenomenally conscious memory of this perceptual state, including its content, supposedly partly constitutes the cognitive map that is needed to provide her experience at $t_{2}$ with a content - to enable this experience to present her with an apple.

So, the claim that no more than objectivity ${ }_{2}$ is needed for genuine perceptual content is supported not only by the intuitive appeal of the claim that the amnesia patient's perceptual experience is not impaired by her memory loss. It has the added advantage of bypassing the

\footnotetext{
15 Burge (2009) appears to be ambiguous on the claims that the perceptual system or, respectively, the individual, needs to have capacities such as the ability to track a body over time. I thank him for a helpful e-mail on this topic.
} 
strange consequences of the amnesiac case for adherents of the cognitive-map account of objectivity $_{1}$.

In my discussion so far, I have tried to convince the reader that neither integration into a belief- and concept-based world-view nor integration into a nonconceptual cognitive map are required for a subject to have content-bearing perceptual experiences. The solipsist case showed that the apparent empirical import of perceptual experience does not depend on the subject's view of the world as mind-independent. The amnesiac case showed that we cannot count on a perceiver's ability to remember her previous experiences and thus to build up a cognitive map of her surroundings to explain how she can have experiences in which the world appears to present itself to her.

So, apparently, neither the subject's conceptual capacities nor her nonconceptual abilities can be appealed to in an account of perceptual objectivity. Our perceptual experiences present us with features of our environments independently of our appreciation of these features as objective: no more than objectivity ${ }_{2}$ is needed for perceptual content.

This result naturally leads to the question of how perceptual experience comes to represent the perceiver's surroundings to her. Fully answering this question lies outside the scope of this paper. However, let me add a few suggestions which direction an account of perceptual content that does not appeal to further individual-level cognitive capacities might take.

Think of Tye's (1995) PANIC theory, according to which the phenomenal character of experience is due to its nonconceptual content that is (among other things) poised to have an impact on the subject's central cognitive system. My suggestion is that perceptual experience is objective - $_{2}$ it represents features of an objective world to the subject-if there is a corresponding representational output (which already represents distal features of the subject's environment) of a perceptual module that is available to the central cognitive system. The transformation from mere proximal stimulation to representation of distal features takes place inside the perceptual system. No appeal to further cognitive abilities of the individual is made.

Clearly, this suggestion would need an elaboration and a defense. Note, however, that one advantage of explaining the emergence of perceptual content in terms of such subindividual level processes and structures is that this allows that the amnesiac has contentbearing perceptual experiences. Her loss of short-term memory does not affect the work of her perceptual modules. They can still output representations of distal objects and properties, which can be poised to have an impact on the central cognitive system. The amnesiac's problem is that she cannot form new memories on the basis of what she experiences. This is a deficit that lies outside the functioning of her perceptual system-she is unable to remember what she just saw. So, she is unable to create a cognitive map on the basis of her perceptual experience. Many other of her abilities that rely on her short-term memory of perceptual experiences will be impaired as well (e.g., reaching for a hidden object). But that the actual impact of her perceptual experiences on her beliefs and actions will be limited makes no difference for whether the output from the perceptual system will be poised to have an impact on her central cognitive system. ${ }^{16}$ For a discussion of the distinction between individual and sub-individual levels of explanation, see Bermúdez (2005).

\footnotetext{
16 Note that Tye's (1995, 7-10) explication of unilateral visual neglect is in the same spirit: He suggests that a unilateral visual neglect patient has phenomenally conscious visual experiences in the 'neglected' part of her visual field and that her real deficit is of a higher cognitive order-it is her inability to attend to and notice what she experiences.
} 
Consequently, we should accept objectivity 2 , not objectivity ${ }_{1}$, as a necessary condition on perceptual content. Step one of the argument from objectivity is untenable-contentbearing perceptual experience need not present the world to the subject as objective; no appreciation of the mind-independence of the world is needed. What is needed for experience to have genuine content is that it represents the world to the subject. I have argued that we cannot appeal to her individual-level capacities to explain how perceptual experience can represent the world, and suggested that we should look to the subject's subindividual cognitive organization instead.

\section{Conclusion}

I started out by presenting the objection from objectivity: Perceptual content must represent the world to the subject as objective; it can do so only if it is rationally integrated into a world-view, and it can be integrated into a world-view only if it is conceptual. So perceptual content must be conceptual, and nonconceptualism is false.

To defend nonconceptualism, I presented two attacks on different steps of the argument. The first objection I presented is directed at step two (A), the claim that rational integration into a (belief- and concept-based) world-view is necessary for perceptual objectivity. The solipsist case shows that even a subject who lacks such a world-view can have perceptual experience apparently presenting the subject with an objective world. I provided an alternative account of what is needed for perception of the world as objective, viz., integration of perceptual experiences into a cognitive map of her environment.

Second, I objected to step one: representation of the world as objective is not required for perceptual experience to have a content-not even if this takes the shape of the perceptual experience's being integrated into a (nonconceptual) cognitive map. I argued that an amnesiac's memory loss does not affect her perceptual experience itself, even if it impairs her ability to build up a cognitive map. Moreover, I pointed out that requiring possession of a cognitive map leads to strange consequences if the amnesiac is healed. Apparently, a perceptual state that did not have a representational content at the time can be the source of a genuine content-bearing memory of what the perceiver was not perceptually confronted with originally.

I conclude that the argument from objectivity cannot support conceptualism. On my view, the nonconceptualist should not grant that perceptual content presupposes the subject's ability to appreciate the mind-independence of the world in any sense. Rather, the subject has a content-bearing perceptual experience only if the world is present to her in perception. In order to elucidate this claim, we do not have to appeal to further individuallevel capacities. Instead, I suggested, we need a sub-individual level account of how the perceptual system generates representations of a mind-independent world that are poised to influence the central cognitive system.

It is likely that this account will not satisfy my conceptualist opponent. His fear of the blindness of perceptual experience calls for the subject to understand that she is confronted with a mind-independent world. An appeal to sub-individual processes will not be able to assuage his fear.

The conceptualist's worry is caused by his misconception of his and the nonconceptualist's dialectical situation. What motivates him is the specter of a perceptual experience that does not present the subject with the world around her, but with raw feels, from which she is supposed to draw conclusions about her surroundings. It is admittedly impossible to construct representational experiences from this starting-point. But this is not the 
nonconceptualist's view. The nonconceptualist assumes that experience already comes with representational content. I have suggested that, in order to understand how this is possible, we should turn to the sub-individual processes investigated by cognitive scientists. $^{17}$

\section{References}

Bermúdez, J. (2003). Nonconceptual content: From perceptual experience to subpersonal computational states. In Y. Gunther (Ed.), Essays on nonconceptual content (pp. 183-216). Cambridge, MA: Bradford Books.

Bermúdez, J. (2005). Philosophy of psychology: A contemporary introduction. New York: Routledge.

Brewer, B. (1999). Perception and reason. Oxford: Clarendon Press.

Burge, T. (2009). Perceptual objectivity. Philosophical Review, 118, 285-324.

Burge, T. (2010). Origins of objectivity. New York: Oxford University Press.

Byrne, A. (2005). Perception and conceptual content. In M. Steup \& E. Sosa (Eds.), Contemporary debates in epistemology (pp. 231-250). Malden, MA: Blackwell.

Crane, T (2011), The problem of perception, In E. N. Zalta (Ed.), The Stanford encyclopedia of philosophy. (Spring 2011 Edition), URL:http://plato.stanford.edu/archives/spr2011/entries/perception-problem/.

Davidson, D. (1983/2008). A coherence theory of truth and knowledge. In E. Sosa et al. (Eds), Epistemology: An anthology (pp. 154-164). Malden, MA: Blackwell.

Evans, G. (1982). The varieties of reference. Oxford: Clarendon Press.

McDowell, J. (1994a). The content of perceptual experience. The Philosophical Quarterly, 44, 190-205.

McDowell, J. (1994b). Mind and world. Cambridge, MA: Harvard University Press.

Peacocke, C. (1992). A study of concepts. Cambridge, MA: MIT Press.

Peacocke, C. (1994). Non-conceptual content: Kinds, rationales and relations. Mind and Language, 9 , 419-429.

Peacocke, C. (2001a). Does perception have a nonconceptual content? Journal of Philosophy, 98, 239-264.

Peacocke, C. (2001b). Phenomenology and nonconceptual content. Philosophy and Phenomenological Research, 62, 609-615.

Peacocke, C. (2003). Postscript: The relations between conceptual and nonconceptual content. In Y. Gunther (Ed.), Essays on nonconceptual content (pp. 318-322). Cambridge, MA: Bradford Books.

Proust, J. (2000). L'animal intentionnel. Terrain, 34, 23-36.

Quine, W. V. O. (1960). Word and object. Cambridge, MA: MIT Press.

Schmidt, E. (forthcoming). Modest nonconceptualism. (Studies in brain and mind series). Dordrecht: Springer.

Strawson, P. (1959). Individuals: An essay in descriptive metaphysics. London: Methuen.

Tye, M. (1995). Ten problems of consciousness. Cambridge, MA: MIT Press.

17 These considerations naturally lead to questions of how talk of content in individual-level is related to content-talk in sub-individual-level explanations. I discuss this issue in my (forthcoming). 